\title{
木材のモード I の破壊じん性值の測定におよぼす試験方法の影響†
}

\author{
吉 原浩* 川 村 拓 司** \\ Influence of the Measurement Methods on the Mode I Fracture Toughness of Wood
}

by

Hiroshi Yoshinara * and Takuji Kawamura **

In this work, we examined the validity of four methods for measuring the mode I fracture toughness of wood; double cantilever beam (DCB), compact tension (CT), single edge notched tension (SENT), and single edge notched bending (SENB) tests, which have been frequently conducted. In the fracture tests, the crack length was variously changed, and the validity of each method was evaluated by the dependence of fracture toughness on the crack length. From the comparisons of fracture toughnesses obtained by the different four methods, the DCB test was more recommended than any other methods because the fracture toughness could be appropriately obtained in the wide range of crack length.

Key words : Mode I fracture toughness, DCB test, CT test, SENT test, SENB test

\section{1 緒言}

材料の強度的性質を評価する上で破壊力学はきわめて 有効な手段であり, 木材でもこれまで破壊力学に基づいた 強度特性の評価についてさまざまに検討されてきた.1) -4) 特に開口モード（モード I）の破壊じん性值は，一般的に 他の 2 つのモードの破壊じん性值に比べて小さく，モー ドIによる破壊の発生および進展が生じやすいために重 要視されており，今世紀に入ってもな打多くの研究成果 が報告されている.5) 17) しかし, 従来の報告の多くはひ とつの試験法から得られた破壊じん性值を用いている場 合が多く，異なった試験法から得られたモードIの破壊

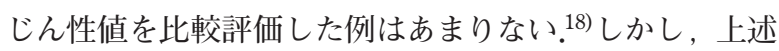
したように材料の強度的性質を評価における破壊力学的 手法の有効性が認められつつあることを考えると，これ まで以上に木材の破壊じん性試験がより頻繁に実施され るようになり, 試験法の整備が要求されるようになるこ とが予想される。こうした意味で，いずれの方法によっ て適切に破壊じん性值が評価できるか検討することは， 安定した破壊じん性值を測定する上できわめて重要であ ると考えられる。そこで, 本研究では異なる 4 つの方法 でさまざまなき裂長さをもつ木材のモードI の破壊じん 性值を測定し, 得られた破壊じん性值を互いに比較する ことによって測定法の検討を試みた。

\section{$2 \cdot 1$ 供試材}

\section{2 実 験 方 法}

本研究では気乾状態で密度が $0.49 \pm 0.01 \mathrm{~g} / \mathrm{cm}^{3}$ のベイ ツガ (Tsuga heterophylla Sarg.) の角材を使用した。使用 した角材には節や繊維の乱れなどの欠点はなく，この角 材から作製した試験体は「無欠点小試験体」であると見
なすことができた。この角材を温度 $20^{\circ} \mathrm{C}$ ，相対湿度 $65 \%$ の部屋で調湿し，ここで使用したすべての試験体をこの 角材から採取した。モードIの破壊じん性值を，破壊じ ん性試験として比較的頻繁に実施される方法である双片 持ちばり (DCB) 試験, コンパクト引張 (CT) 試験, 片側 クラック引張 $(\mathrm{SENT})$ 試験および片側クラック 3 点曲げ 試験 (SENB) 試験で求めた。なお，すべてき裂は繊維方 向に沿って導入し，接線方向に開口するように荷重を負 荷した (TL システム)。また，破壊じん性試験ではき裂 長さをさまざまに変化させ，1つのき裂長さについて 5 体の試験体を使用した。各試験の概要を以下に示す。

\section{$2 \cdot 2$ DCB 試験}

Fig. 1 にDCB 試験の概要を示す。試験体の寸法を $15 \mathrm{~mm}$ (半径方向 $) \times 15 \mathrm{~mm}$ (接線方向 $) \times 315 \mathrm{~mm}$ (繊 維方向）とした。あさり幅 $1 \mathrm{~mm}$ の帯のこを用いて所定 の長さまでき裂を入れた後，片刃のカミソリを用いてき 裂先端を $1 \mathrm{~mm}$ 伸長させた. き裂の導入後, 高さ $30 \mathrm{~mm}$, 長さ $30 \mathrm{~mm}$ および幅 $15 \mathrm{~mm}$ で半径 $7 \mathrm{~mm}$ の円孔を有する ベイッガのブロックを Fig. 1のように試験体の片持ちば り部分の上下に接着した。き裂長さ $a$ は荷重線とき裂先

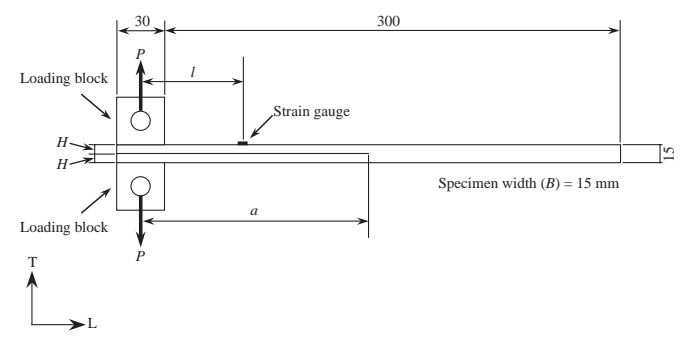

Fig. 1 Schematic diagram of the DCB test.

$\dagger$ 原稿受理 平成 18 年 5 月 1 日 Received May 1, 2006 @ 2007 The Society of Materials Science, Japan

* 正 会 員 島根大学総合理工学部材料プロセス工学科 †690-8504 松江市西川津町, Dept. of Natural Resources Process Eng., Shimane Univ., Nishikawatsu-cho, Matsue, 690-8504

** 東京大学大学院農学生命科学研究科生物材料工学専攻 ₹113-8657 東京都文京区弥生, Dept. of Biomaterial Sci., The Univ. Tokyo, Bunkyo-ku, Tokyo, 113-8657 
端の距離で定義し, $90 \mathrm{~mm}$ から $210 \mathrm{~mm}$ まで $30 \mathrm{~mm}$ 間隔の き裂長さを持つ試験体を準備した。 DCB 試験や ENF 試 験などの曲げに依拠した破壊じん性試験では，き裂先端 における特異な変形によって荷重一たわみ関係が初等は り理論から逸脱することが知られているが 4), 16), 17), 19) 22) 試験体の特定部分のひずみを同時に測定することによっ てはり理論からの逸脱を修正して適切に破壊じん性值が 得られることが示され，コンプライアンス結合法として 提案されている.17), 19) 22) ここでは Fig. 10ように片持ち ばり部分における荷重線とき裂先端の中間点における長 手方向のひずみを測定するためにひずみゲージ（東京測器 FLA-2-11，ゲージ長 2mm）を貼付した。荷重点ブロック に通した鋼製のピンを介し，クロスヘッド速度 $5 \mathrm{~mm} / \mathrm{min}$ で明らかに荷重が低下するまで引張負荷を続け, 荷重 $P$, 荷重点の変位 $\delta$ および荷重線とき裂先端の中間点におけ るひずみ $\varepsilon_{\mathrm{x}}$ を測定した。 $P-\delta$ 関係および $P-\varepsilon_{\mathrm{x}}$ 関係の直 線部分の傾きから, 荷重点コンプライアンス $C_{\mathrm{L}}$ およびひ ずみコンプライアンス $C_{\mathrm{S}}$ を求めた。 また，き裂進展開始 時の荷重 $P_{\mathrm{c}}$ は $P-\delta$ 関係の初期直線部分の傾きの $5 \%$ 減じ た傾きをもつ直線と $P-\delta$ 曲線の交点で定義した，以上に 示した $P_{\mathrm{c}}, C_{\mathrm{L}}$ および $C_{\mathrm{S}}$ の值を用いて，エネルギー解放 率の臨界值 $G_{\mathrm{Ic}}$ をコンプライアンス結合法に基づく以下 の式から求めた. ${ }^{17)}$

$$
G_{\mathrm{Ic}}=\frac{3 P_{\mathrm{c}}^{2} C_{\mathrm{L}}}{2 B}\left(\frac{3 H l}{4} \cdot \frac{C_{\mathrm{L}}}{C_{\mathrm{S}}}\right)^{-\frac{1}{3}}
$$

ここで $B$ は試験体の幅, $H$ は片持ちばり部分の高さであ る。また, Fig. 1 に示すように $l$ は荷重点からひずみの 測定点までの距離で，ここでは $l=a / 2$ である.

\section{$2 \cdot 3 \mathrm{CT}$ 試験}

Fig. 2 に CT 試験の概要を示す. 試験体の寸法は $15 \mathrm{~mm}$ (半径方向 $) \times 120 \mathrm{~mm}$ (接線方向 $) \times 125 \mathrm{~mm}$ （䋊維方向 $)$ とした。上述した DCB 試験と同様の方法で試験体にき 裂を導入した。き裂長さ $a$ は荷重線とき裂先端の距離で 定義し，30mm から $70 \mathrm{~mm}$ まで $10 \mathrm{~mm}$ 間隔のき裂長さ を持つ試験体を準備した。また，Fig. 2 のような位置に 荷重点を負荷するための円孔を開けた。この円孔に通し た鋼製のピンを介し，クロスヘッド速度 $2 \mathrm{~mm} / \mathrm{min}$ で明 らかに荷重が低下するまで引張負荷を続け，荷重 $P$ およ び荷重点の変位 $\delta$ を測定した。 き裂進展開始時の荷重 $P_{\mathrm{c}}$ は DCB 試験と同様の方法で求めた。

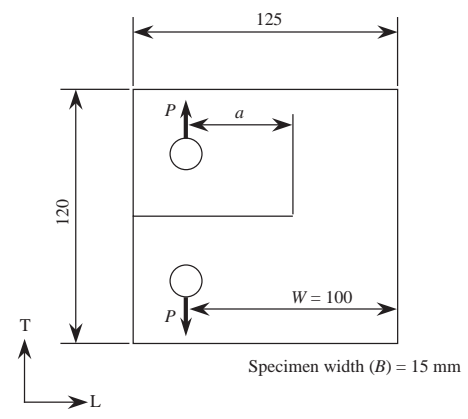

Fig. 2 Schematic diagram of the CT test
応力拡大係数の臨界值 $K_{\mathrm{Ic}}$ を以下の近似式から求めた 23$)$

$$
\begin{aligned}
K_{\mathrm{Ic}}= & \frac{P_{\mathrm{c}} \sqrt{a}}{B W}\left[29.6-185.5\left(\frac{a}{W}\right)+655.7\left(\frac{a}{W}\right)^{2}\right. \\
& \left.-1017.0\left(\frac{a}{W}\right)^{3}+638.9\left(\frac{a}{W}\right)^{4}\right]
\end{aligned}
$$

ここで $W$ は Fig. 2 のように荷重点からき裂の進行方向 の試験体端部までの距離である.

\section{$2 \cdot 4$ SENT 試験}

Fig. 3 にSENT 試験の概要を示す．使用した角材の寸 法から，接線方向に十分な長さを持つ試験体を作製する ことが困難であったため, この図のようにエポキシ系接着 剤を使用して接線方向に接着し, 最終的な試験体の寸法 を $15 \mathrm{~mm}$ (半径方向 $) \times 200 \mathrm{~mm}$ (接線方向 $) \times 40 \mathrm{~mm}$ （繊 維方向）とした。前述した 2 つ試験と同様の方法で試 験体にき裂を導入した。き裂長さ $a$ は試験体の縁とき裂 先端の距離で定義し， $12 \mathrm{~mm}$ から $28 \mathrm{~mm}$ まで $4 \mathrm{~mm}$ 間隔 のき裂長さを持つ試験体を準備した，材端から $40 \mathrm{~mm} の$ 長さで試験体をつかみ，クロスヘッド速度 $1 \mathrm{~mm} / \mathrm{min}$ で 明らかに荷重が低下するまで負荷を続け，荷重 $P$ および 荷重点の変位 $\delta$ を測定した．前述した 2 つの試験と同様 にき裂進展開始時の荷重 $P_{\mathrm{c}}$ を求めた。

$K_{\mathrm{Ic}}$ 值は以下の近似式から算出した. ${ }^{24)}$

(i) き裂長さが $12 \mathrm{~mm}$ から $20 \mathrm{~mm}$ のとき

$K_{\mathrm{Ic}}=\frac{P_{\mathrm{c}} \sqrt{\pi a}}{B W}\left[0.265\left(1-\frac{a}{W}\right)^{4}+\left(0.857+0.265 \frac{a}{W}\right)\left(1-\frac{a}{W}\right)^{-\frac{3}{2}}\right]$

(ii) き裂長さが $24 \mathrm{~mm}$ および $28 \mathrm{~mm}$ のとき

$$
\begin{aligned}
K_{\mathrm{Ic}}= & \frac{P_{\mathrm{c}} \sqrt{\pi a}}{B W}\left[1.12-2.31\left(\frac{a}{W}\right)+10.55\left(\frac{a}{W}\right)^{2}\right. \\
& \left.-21.72\left(\frac{a}{W}\right)^{3}+30.39\left(\frac{a}{W}\right)^{4}\right]
\end{aligned}
$$

ここで $W$ は試験体の幅である.

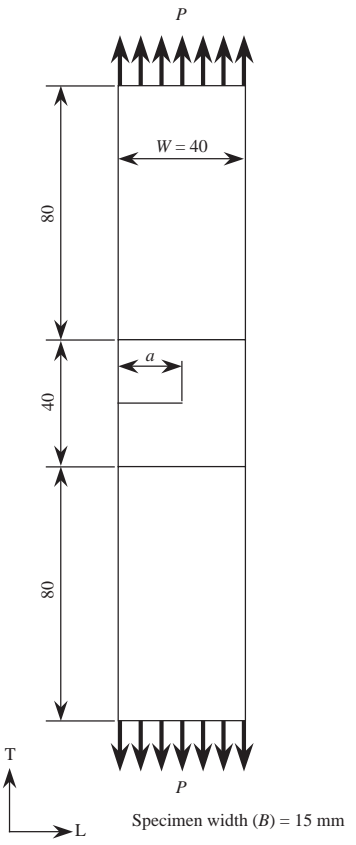

Fig. 3 Schematic diagram of the SENT test 


\section{$2 \cdot 5$ SENB 試験}

Fig. 4 に SENB 試験の概要を示す. SENT 試験と同様 に接線方向に十分な長さを持つ試験体を調製することが 困難であったため, エポキシ系接着剤を使用して接線方向 に接着し, 最終的な試験体の寸法を $15 \mathrm{~mm}$ (半径方向) $\times$ $200 \mathrm{~mm}$ (接線方向 $) \times 40 \mathrm{~mm}$ (繊維方向) とした. 前述し た 3 つの試験と同様の方法で試験体にき裂を導入した. き 裂長さ $a$ は試験体の縁とき裂先端の距離で定義し, $12 \mathrm{~mm}$ から $28 \mathrm{~mm}$ まで $4 \mathrm{~mm}$ 間隔のき裂長さを持つ試験体を準 備した。スパンを $160 \mathrm{~mm}$ としてき裂の反対側からクロ スヘッド速度 $0.5 \mathrm{~mm} / \mathrm{min}$ で荷重を負荷し, 荷重 $P$ およ び荷重点の変位 $\delta$ を測定した。ここでも以上の試験と同 様の定義にしたがってき裂進展開始時の荷重 $P_{\mathrm{c}}$ を求め, $K_{\text {Ic }}$ 值を以下の近似式から算出した. ${ }^{25)}$

$$
\begin{aligned}
K_{\mathrm{Ic}}= & \frac{6 P_{\mathrm{c}} \sqrt{\pi a}}{B W}\left[1.090-1.735\left(\frac{a}{W}\right)+8.20\left(\frac{a}{W}\right)^{2}\right. \\
& \left.-14.18\left(\frac{a}{W}\right)^{3}+14.57\left(\frac{a}{W}\right)^{4}\right]
\end{aligned}
$$

ここで $W$ は試験体の高さである.

\section{$2 \cdot 6 K_{I c}$ 值と $G_{I c}$ 值の互換に必要な弾性定数の測定}

式 (2)，(3)，(4)で得られた $K_{\mathrm{Ic}}$ 值は $G_{\mathrm{Ic}}$ 值に変換する ことが可能である。一方, 式 (1)で得られた $G_{\mathrm{Ic}}$ 值は $K_{\mathrm{Ic}}$ 值に変換することが可能である。したがって，ここでは 変換に必要なべイツガの弾性定数を Fig. 5 に示すような 4 点曲げ試験および非対称 4 点曲げ試験を行うことによ り求めた.

繊維方向のヤング率 $E_{\mathrm{L}}$ および板目面のポアソン比 $v_{\mathrm{LT}}$ は, 長手方向が䋊維方向と一致した試験体の 4 点曲げ試 験で求めた。破壊じん性試験に使用した角材から $300 \mathrm{~mm}$ (繊維方向 $) \times 15 \mathrm{~mm}$ (接線方向 $) \times 10 \mathrm{~mm}$ (半径方向 $)$ の 試験体を切り出した。試験体の板目面中央に 3 軸のひず みゲージ（東京測器 FRA-2-11，ゲージ長 2mm）を貼付 した。スパンを $270 \mathrm{~mm}$ とし，ゲージがスパン中央下部 に位置するように試験体を置いた。スパンの 3 等分点に クロスヘッド $2 \mathrm{~mm} / \mathrm{min}$ で荷重を負荷し, 荷重 $P, \mathrm{~L}$ 方 向のひずみ $\varepsilon_{\mathrm{L}}$ および $\mathrm{T}$ 方向のひずみ $\varepsilon_{\mathrm{T}}$ を測定した。 以 下の式から $E_{\mathrm{L}}$ および $v_{\mathrm{LT}}$ を求めた。

$$
\left\{\begin{array}{l}
E_{\mathrm{L}}=\frac{l}{b h^{2}} \cdot \frac{\Delta P}{\Delta \varepsilon_{\mathrm{L}}} \\
v_{\mathrm{LT}}=-\frac{\Delta \varepsilon_{\mathrm{T}}}{\Delta \varepsilon_{\mathrm{L}}}
\end{array}\right.
$$

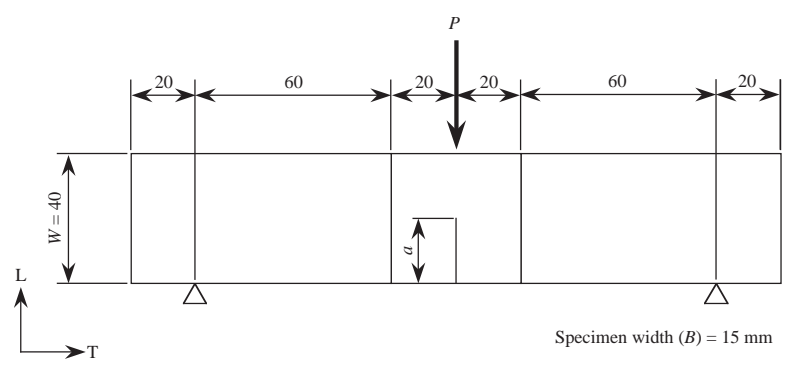

Fig. 4 Schematic diagram of the SENB test.

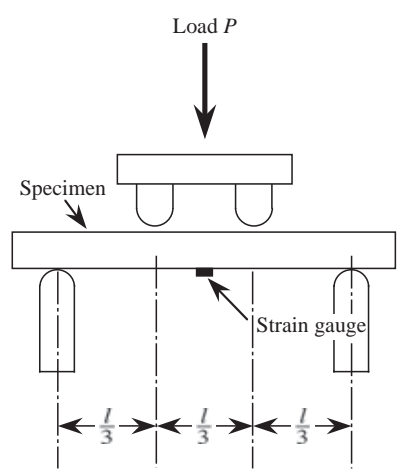

(a) Four-point bending test

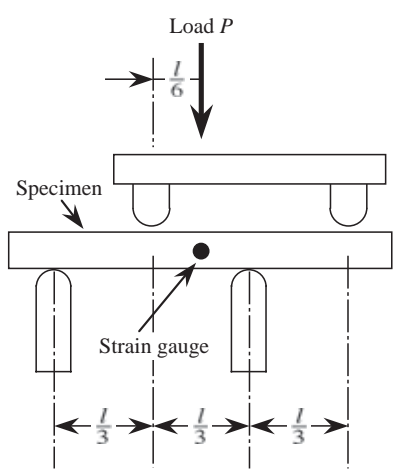

(b) Asymmetric four-point bending test
Fig. 5 Bending test diagrams for measuring the elastic constants.

ここで $l$ はスパン長,$b$ は試験体の幅, $h$ は試験体の高 さ, $\Delta P / \Delta \varepsilon_{\mathrm{L}}$ および $\Delta \varepsilon_{\mathrm{L}} / \Delta \varepsilon_{\mathrm{T}}$ はそれぞれ $P-\varepsilon_{\mathrm{L}}$ 関係と $\varepsilon_{\mathrm{L}}-\varepsilon_{\mathrm{T}}$ 関係の初期の傾きである。試験体の個数は 5 体とした. 一方，この試験体を使用し，Fig. 5 (b)のようにゲージが スパン中央の側面になるように配置して非対称 4 点曲げ 試験を行うことによって板目面のせん断弾性係数 $G_{\mathrm{LT}}$ を 求めた。クロスヘッド速度は $2 \mathrm{~mm} / \mathrm{min}$ とし, 荷重 $P$, 繊維方向のひずみ $\varepsilon_{\mathrm{L}}$, 接線方向のひずみ $\varepsilon_{\mathrm{T}}$, および緎維 方向から $45^{\circ}$ 傾いた方向のひずみ $\varepsilon_{45}$ を測定した。以下 の式から $G_{\mathrm{LT}}$ を求めた. ${ }^{26)}$

$$
G_{\mathrm{LT}}=\frac{3}{4 b h} \cdot \frac{\Delta P}{\Delta \gamma}
$$

ここで $\gamma$ はせん断ひずみで, 以下の式から与えられる。

$$
\gamma=2 \varepsilon_{45}-\varepsilon_{\mathrm{L}}-\varepsilon_{\mathrm{T}}
$$

接線方向のヤング率 $E_{\mathrm{T}}$ は長手方向が接線方向と一致 した試験体の 4 点曲げ試験で求めた。破壊じん性試験に 使用した角材から $15 \mathrm{~mm}$ (繊維方向) $\times 140 \mathrm{~mm}$ （接線方 向 $) \times 10 \mathrm{~mm}$ (半径方向) の試験体を切り出した. 試験体 の板目面中央に単軸のひずみゲージ（東京測器 FLA-2-11, ゲージ長 $2 \mathrm{~mm}$ ）を貼付した. スパンを $120 \mathrm{~mm}$ とし，ゲー ジがスパン中央下部に位置するように試験体を置いた。 スパンの 3 等分点にクロスヘッド $2 \mathrm{~mm} / \mathrm{min}$ で荷重を負 荷し, 荷重 $P$ および $\mathrm{T}$ 方向のひずみ $\varepsilon_{\mathrm{T}}$ を測定した。以 下の式から $E_{\mathrm{T}}$ を求めた.

$$
E_{\mathrm{T}}=\frac{l}{b h^{2}} \cdot \frac{\Delta P}{\Delta \varepsilon_{\mathrm{T}}}
$$

この場合も試験体の個数は 5 体とした.

$K_{\mathrm{Ic}}$ 值は以下の式で $G_{\mathrm{Ic}}$ 值に変換することができる. ${ }^{27)}$

$$
G_{\mathrm{Ic}}=K_{\mathrm{Ic}}^{2}\left(\frac{S_{11} S_{22}}{2}\right)^{\frac{1}{2}}\left[\left(\frac{S_{11}}{S_{22}}\right)^{\frac{1}{2}}+\frac{2 S_{12}+S_{66}}{2 S_{11}}\right]^{\frac{1}{2}}
$$

ここで $S_{11}=1 / E_{\mathrm{L}}, S_{22}=1 / E_{\mathrm{T}}, \quad S_{12}=-v_{\mathrm{LT}} / E_{\mathrm{L}}, \quad S_{66}=$ $1 / G_{\mathrm{LT}}$ である。各弾性定数の平均值および式 (2), (3), (4)で得られた $K_{\mathrm{Ic}}$ 值を式 (9)に代入して $G_{\mathrm{Ic}}$ 值を求めた. 一方，式 (1)で得られた $G_{\text {Ic }}$ 值を式 (9)に代入して $K_{\text {Ic }}$ 值 を求めた。 


\section{3 結 果と考 察}

Table $1 に 4$ 点曲げ試験打よび非対称 4 点曲げ試験で 得られた繊維方向のヤング率 $E_{\mathrm{L}}$, 接線方向のヤング率 $E_{\mathrm{T}}$, 板目面のポアソン比 $v_{\mathrm{LT}}$ および板目面のせん断弾性 係数 $G_{\mathrm{LT}}$ を示す。上述したように, CT 試験，SENT 試 験およびSENB 試験で得られた応力拡大係数の臨界值 $K_{\mathrm{Ic}}$ をこれらの弾性定数の平均值を用いてエネルギー解放 率の臨界值 $G_{\mathrm{Ic}}$ に変換した。一方, DCB 試験で得られた エネルギー解放率の臨界值 $G_{\mathrm{Ic}}$ をこれらの弾性定数の平均 值を用いて応力拡大係数の臨界值 $K_{\mathrm{Ic}}$ に変換した。 Fig. 6 に各方法で得られた $G_{\mathrm{Ic}}$ 值とき裂長さの関係を示す。ま た, Fig. 7 に各方法で得られた $K_{\mathrm{Ic}}$ 值とき裂長さの関係 を示す.

Fig. 6 から，DCB 試験ではき裂長さにかかわらずほぼ 一定した $G_{\text {Ic }}$ 值が得られた。また，標準偏差の值も他の 方法で得られたものよりも小さく, DCB 試験が $G_{\text {IC }}$ 值の 測定に非常に効果的な方法であることが示された。これ に対し，CT 試験で得られた $G_{\mathrm{Ic}}$ 值は，き裂長さが短くな ると大きくなる傾向を示し, 反対にSENT 試験で得られ た $G_{\text {Ic }}$ 值はき裂長さが長くなると大きくなる傾向を示し た。ただし，き裂長さの範囲を限定するならば，これら の試験で得られた $G_{\mathrm{Ic}}$ 值は DCB 試験で得られた値と比較 的近い値を示して打り，破壊じん性值が適切に求められ る可能性があると思われる。 また, SENB 試験で得られ

Table 1 Elastic constants obtained by the symmetric and asymmetric four-point bending tests.

\begin{tabular}{cccc}
\hline$E_{\mathrm{L}}(\mathrm{GPa})$ & $E_{\mathrm{T}}(\mathrm{GPa})$ & $\nu_{\mathrm{LT}}$ & $G_{\mathrm{LT}}(\mathrm{GPa})$ \\
$16.0 \pm 2.0$ & $0.73 \pm 0.08$ & $0.51 \pm 0.09$ & $0.90 \pm 0.06$ \\
\hline
\end{tabular}

Results are average \pm standard deviations.
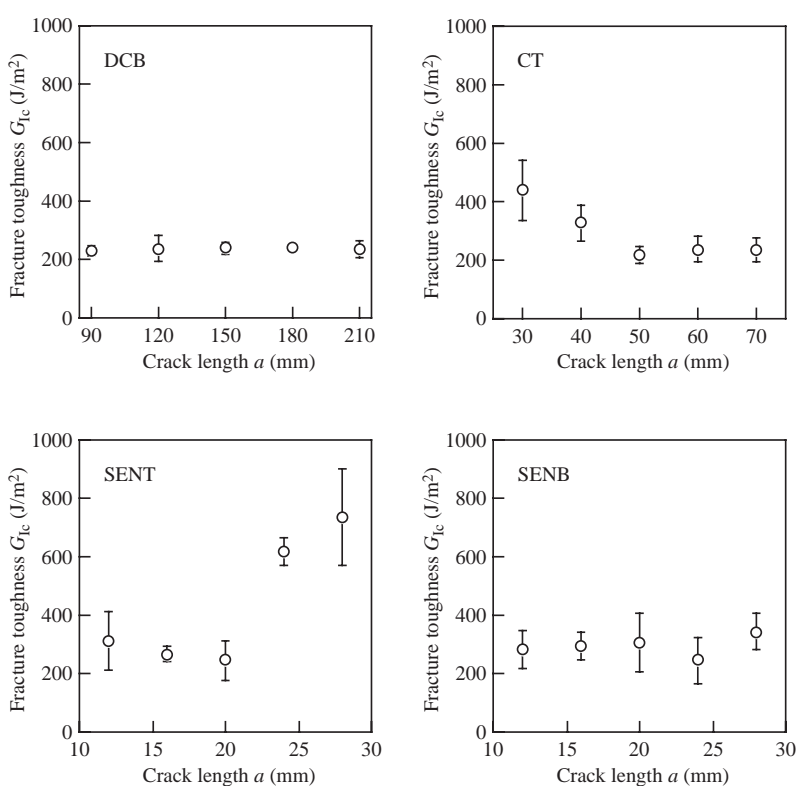

Fig. 6 Comparison of the mode I fracture tougnesses GIc obtained by the different methods. Circles and horizontal bars represent the average and standard deviations, respectively.
た $G_{\text {Ic }}$ 值はき裂長さにあまり依存せず，先の平均值は DCB 試験で得られた值と比較的近くなった。ただし，DCB 試 験に比べて標準偏差が大きく，試験の安定性を考えれば DCB 試験の方がより優れた方法であると考えられる.ま た式 (9)から， $K_{\mathrm{Ic}}$ 值については $G_{\mathrm{Ic}}$ 值に比べてき裂長さ による変動は少なくなるが, Fig. 7 に示されるようにCT 試験やSENT 試験の結果にはき裂長さの依存性が明白で あった。一方，DCB 試験がもっとも安定した結果が得ら れたという点は $G_{\mathrm{IC}}$ 值の傾向と同様であった。

以上のことから，き裂長さ依存性や破壊じん性值の変 動の小ささを考慮すると，ここで検討した 4 つの方法の 中では DCB 試験が破壊じん性值を安定的に測定できる もっとも適切な試験法であると思われる。一方， DCB 試 験を除く 3 つの試験法では $K_{\mathrm{Ic}}$ 值を算出する際に近似式 を使用しているが，ここで示された $G_{\mathrm{Ic}}$ 值や $K_{\mathrm{IC}}$ 值のき裂 長さ依存性から，き裂長さが広い範囲で木材の破壊じん 性值が適切に得られるような近似式の提案が必要である と思われる。

\section{4 結 論}

本研究ではモード I の破壞じん性試験として比較的実 施される頻度が比較的高い 4 つの方法（DCB 試験，CT 試験，SENT 試験およびSENB 試験）で，さまざまなき 裂長さをもつべイツガの破壞じん性值を測定し，各方法 の妥当性について検討した。呪の結果，き裂長さの範囲 を限定すれば，ここで検討した 4 つの方法で適切に破壊 ビん性值を評価できる可能性が示唆されたが，中でも DCB 試験はき裂長さの影響が小さく，もっとも安定的に 破壞じん性值を測定できると思われた。
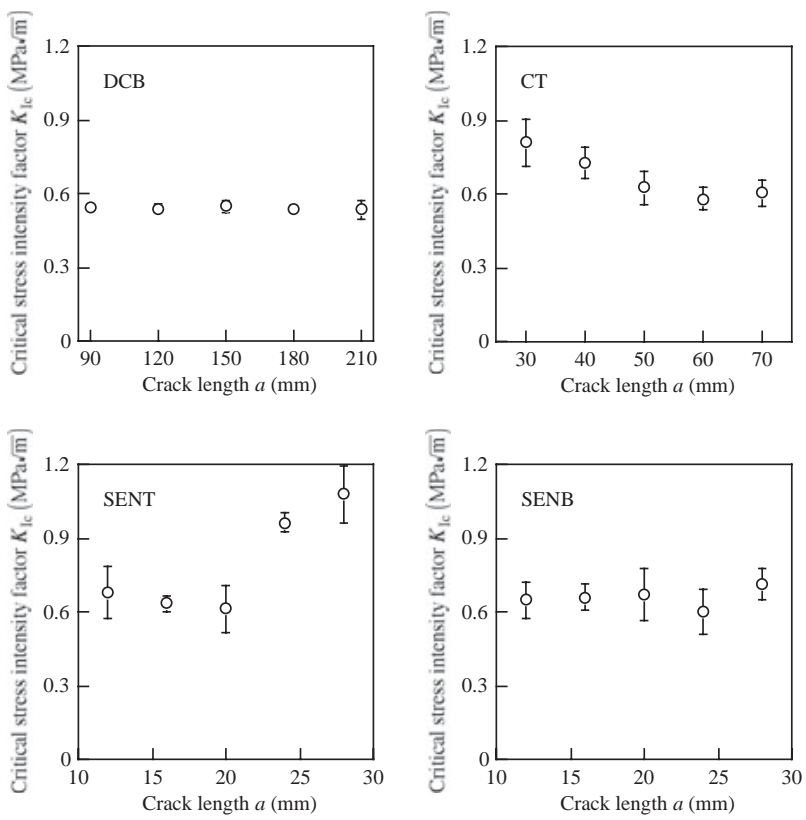

Fig. 7 Comparison of the mode I critical stress intensity factors $K_{\text {Ic }}$ obtained by the different methods. Circles and horizontal bars are similar to those in Fig. 6. 


\section{参 考 文 献}

1) A. W. Porter, "On the mechanics of fracture in wood", Forest Products Journal, Vol.14, No.8, pp.325-331 (1964).

2 ) M. Patton-Mallory, "Fracture mechanics : a tool for predicting wood component strength”, Forest Products Journal, Vol.37, No.7/8, pp.40-47 (1987).

3 ) M. P. Conrad, G. D. Smith and G. Fernlund, "Fracture of solid wood : a review of structure and properties at different scales”, Wood and Fiber Science, Vol.35, No.4, pp.570-584 (2003).

4) H. Yoshihara, "Characterization of fracturing properties of wood and wood materials based on the fracture mechanics", Mokuzai Gakkaishi, Vol.52, No.4, pp.185-195 (2006).

$5)$ E. K. Tschegg, K. Frühmann and S. E. Stanzl-Tschegg, "Damage and fracture mechanisms during mode I and III loading of wood”, Holzforschung, Vol.55, No.5, pp.525-533 (2001).

6 ) A. Reiterer, G. Sinn, S. E. Stanzl-Tschegg, "Fracture characteristics of different wood species under mode I loading perpendicular to the grain”, Materials Science and Engineering A, Vol.A332, No.1, pp.29-36 (2002)

7 ) S. Vasic and I. Smith, "Bridging crack model for fracture of spruce”, Engineering Fracture Mechanics, Vol.69, No.6, pp.745-760 (2002).

$8)$ S. Vasic, I. Smith and E. Landis, "Fracture zone characterization-micro-mechanical study”, Wood and Fiber Science, Vol.34, No.1, pp.42-56 (2002).

9 ) S. Morel, G. Mourot and J. Schmittbuhl, "Influence of the specimen geometry on R-curve behavior and roughning of fracture surfaces", Vol.121, No.1, pp.23-42 (2003).

10) K. Frühmann, I. Burgert, I. E. K. Tschegg and S. E. StanzlTschegg, "Mode I fracture behaviour on the growth ring scale and cellular level of spruce (Picea abies [L.] Karst.) and beech (Fagus sylvatica L.) loaded in the TR crack propagation system”, Holzforschung, Vol.57, No.6, pp.326-332 (2003).

11) S. Vasic and I. Smith, "Contact-crack problem with friction in spruce”, Holz als Roh-und Werkstoff, Vol.61, No.3, pp.182-186 (2003).

12) I. Smith and S. Vasic, "Fracture behaviour of softwood", Mechanics of Materials, Vol.35, No.8, pp.803-815 (2003).

13) M. Scheffler, P. Niemz, M. Diener and V. Lustig, "Untersuchungen zur Ermittlung der Bruchzähigkeit an Laubholz in den Rissöffnungsmodi I und II”, Holz als Roh-und Werkstoff, Vol.62, No.2, pp.93-100 (2004).

14) S. Samarasinghe and D. Kulasiri, "Stress intensity factor of wood from crack-tip displacement fields obtained from digital image processing”, Silva Fennica, Vol.38, No.3, pp.267-278 (2004).

15) S. Morel, N. Dourado, G. Valentin, J. Morais, "Wood : a quasibrittle material R-curve behavior and peak load evaluation”, International Journal of Fracture, Vol.131, No.4, pp.385-400 (2005).

16) J. L. Jensen, "Quasi-non-linear fracture mechanics analysis of the double cantilever beam specimen”, Journal of Wood Science, Vol.51, No.6, pp.566-571 (2005).

17) H. Yoshihara and T. Kawamura, "Mode I fracture toughness estimation of wood by DCB test", Composites Part A, Vol.37, No.11, pp.2105-2113 (2006).

18) N. Suzuki, "Fracture toughness of wood and wood products", Final Report of a Grant-in-Aid for Scientific Research Project 1994-1995 (No.06302069), pp.129-135 (1996).

19) H. Yoshihara, "Mode II R-curve of wood measured by 4-ENF test”, Engineering Fracture Mechanics, Vol.71, No.13/14, pp.2065-2077.

20) H. Yoshihara, "Mode II initiation fracture toughness analysis for wood by 3-ENF test", Composites Science and Technology, Vol.65, No.14, pp.2198-2207 (2005).

21) H. Yoshihara "Examination of the 4-ENF test for measuring the mode III $R$-curve of wood”, Engineering Fracture Mechanics., Vol.73, No.1, pp.42-63 (2006).

22) H. Yoshihara "Influence of crack length on the measurement of mode II initiation fracture toughness of wood by three-point bend end-notched flexure (3ENF) test", Transactions of the Japan Society of Mechanical Engineers, Part A, Vol.72, No.1, pp.133-139 (2006).

23) E. T. Wessel, "State of the art of the WOL specimen for $K_{\mathrm{Ic}}$ fracture toughness testing”, Engineering Fracture Mechanics, Vol.1, No.1, pp.77-82 (1968).

24) R. A. Jurf and R. B. Pipes, "Interlaminar fracture of composite materials", Journal of Composite Materials, Vol.16 No.5, pp.386-394 (1982)

25) B. Gross and J. E. Srawley, "Stress-intensity factors for three-point bend specimens by boundary collocation”, NASA Technical Note TN D-3092, pp.1-13 (1966).

26) H. Yoshihara and A. Suzuki, "Shear stress/shear strain relation of wood obtained by asymmetric four-point bending test of side-tapered specimen”, Journal of Testing and Evaluation, Vol.33, No.1, pp.55-60.

27) G. C. Sih, P. C. Paris and G. R. Irwin, "On cracks in rectilinearly anisotropic bodies”, International Journal of Fracture Mechanics, Vol.1, No.3, pp.189-203 (1965). 